\title{
Perfis dos produtores, comerciantes e consumidores de mel da cidade de Barreiras -
}

\section{Bahia}

\author{
Profiles of honey producers, traders and consumers in the city of Barreiras - Bahia \\ Perfiles de productores, comerciantes y consumidores de miel en la ciudad de Barreiras - Bahia
}

Recebido: 11/11/2021 | Revisado: 17/11/2021 | Aceito: 22/11/2021 | Publicado: 29/11/2021

Luana Regina Pereira Alves

ORCID: https://orcid.org/0000-0003-4677-846X

Instituto Federal de Educação, Ciência e Tecnologia da Bahia, Brasil

E-mail: luanareginaalves@gmail.com

Camila Filgueira de Souza

ORCID: https://orcid.org/0000-0002-1281-009X Instituto Federal de Educação, Ciência e Tecnologia da Bahia, Brasil

E-mail: souza.cf94@gmail.com

Alexandra Mara Goulart Nunes Mamede

ORCID: https://orcid.org/0000-0001-7154-6017 Instituto Federal de Educação, Ciência e Tecnologia da Bahia, Brasil

E-mail: alexandra.mamede@ifba.edu.br

Fábia Silva de Oliveira de Lima

ORCID: https://orcid.org/0000-0002-6588-0497 Instituto Federal de Educação, Ciência e Tecnologia da Bahia, Brasil E-mail: fabialima@ifba.edu.br

Ítalo Abreu Lima

ORCID: https://orcid.org/0000-0003-0559-3688 Instituto Federal de Educação, Ciência e Tecnologia da Bahia, Brasil E-mail: italoabreu@ifba.edu.br

\begin{abstract}
Resumo
Esse estudo teve como objetivo avaliar as condições de comercialização dos méis nas feiras livres da cidade de Barreiras - BA, avaliar o perfil dos consumidores, comerciantes e produtores. Foram aplicados questionários, a fim de traçar o perfil de cada seguimento. Quanto aos hábitos de compra, 43, 6\% dos consumidores, afirmaram preferir adquirir o produto diretamente com o produtor. A procedência do mel, foi o critério justificado por $46,40 \%$ no momento da aquisição do produto, seguido da qualidade $(28,2 \%) .60 \%$ das pessoas relataram que o mel adquirido por eles não possuíam rótulos, apesar da maioria considerar o produto mais confiável com a presença de rótulo. Foi possível observar nas feiras, condições inadequadas de armazenamento do mel, pois além da utilização de embalagens não recomendadas, havia também incidência de luz solar direta nos recipientes que estavam dispostos em bancadas. Apesar de grande parte dos apicultores e meliponicultores informarem que ja participaram de cursos voltados as Boas Práticas de Fabricação de Alimentos, a maioria não coloca em prática na hora de realizar a higienição pessoal, do ambiente de trabalho e nem dos equipamentos utilzados na produção e envase do mel. A pesquisa foi importante para identificação do perfil dos consumidores de mel, é necessário assimilar os desejos e necessidades de quem compra o produto. A maioria dos apicultores e meliponicultores comercializam seus produtos sem rótulo e sem inspeção, e utilizam embalagens reutilizáveis. Pode-se constatar que os locais de comercialização dos produtos, que são as feiras, não possuem condições adequadas de venda, exposição e armazenamento.
\end{abstract}

Palavras-chave: Feira-livre; Qualidade; Mel; Embalagem.

\begin{abstract}
This study aimed at evaluating the commercialization conditions of honey in open fairs in the city of Barreiras - BA, and assessing the profile of consumers, traders and producers. Questionnaires were applied in order to trace the profile of each segment. Regarding the buying habits, $43.6 \%$ of the consumers said they prefer to buy the product directly from the producer. The origin of the honey was the criterion justified by $46.40 \%$ when buying the product, followed by quality (28.2\%). $60 \%$ of the people reported that the honey they bought did not have labels, although the majority considered the product more reliable with the presence of a label. It was possible to observe in the fairs, inadequate honey storage conditions, because besides the use of non-recommended packages, there was also direct sunlight incidence on the containers that were arranged on stands. Although most of the beekeepers and meliponiculturists informed that they have already participated in courses about Good Practices for Food Production, most of them don't put in practice the hygiene of their personal, work environment and the equipment used for honey production and bottling. The research was important to identify the profile of honey consumers, it's necessary to assimilate the wishes
\end{abstract}


and needs of those who buy the product. Most of the beekeepers and meliponiculturists sell their products without label and inspection, and use reusable packages. It can be seen that the places where the products are sold, which are the fairs, do not have adequate conditions of sale, exhibition and storage.

Keywords: Street fair; Quality; Honey; Packaging.

\section{Resumen}

Este estudio tuvo como objetivo evaluar las condiciones para la comercialización de la miel en los mercados abiertos de la ciudad de Barreiras - BA, para evaluar el perfil de consumidores, comerciantes y productores. Se aplicaron cuestionarios para perfilar el perfil de cada seguimiento. En cuanto a los hábitos de compra, el 43,6\% de los consumidores manifestó que prefería comprar el producto directamente al productor. El origen de la miel fue el criterio justificado en un 46,40\% en el momento de la compra del producto, seguido de la calidad. El $60 \%$ de las personas informó que la miel comprada por ellos no tenía etiquetas, a pesar de que la mayoría considera el producto más confiable con la presencia de una etiqueta. Se pudo observar en las ferias, condiciones de almacenamiento inadecuadas para la miel, ya que además del uso de empaques no recomendados, también hubo incidencia de luz solar directa sobre los contenedores que se dispusieron en bancos. Aunque la mayoría de apicultores y apicultores informan que ya han participado en cursos enfocados a Buenas Prácticas de Fabricación de Alimentos, la mayoría no lo ponen en práctica a la hora de realizar la higiene personal, el ambiente de trabajo o los equipos utilizados en la producción y envasado de la miel. La encuesta fue importante para identificar el perfil de los consumidores de miel, es necesario asimilar los deseos y necesidades de quienes compran el producto. La mayoría de los apicultores y apicultores comercializan sus productos sin una etiqueta o inspección y utilizan envases reutilizables. Se puede observar que los lugares donde se comercializan los productos, que son ferias, no cuentan con las condiciones adecuadas para la venta, exhibición y almacenamiento.

Palabras clave: Feria libre; Calidad; Miel; Embalaje.

\section{Introdução}

O mel é um produto naturalmente produzido por abelhas melíferas e é obtido a partir do néctar das flores, de secreções de partes vivas de plantas ou de excreções de insetos sugadores de partes vivas de plantas. É composto por uma solução de açúcares concentrados, principalmente glicose e frutose, os quais influenciam diretamente sua doçura, além de possuir enzimas (invertase, amilase e glico-oxidase), aminoácidos, ácidos orgânicos, minerais, pigmentos e grãos de pólen (Brasil, 2000).

A composição físico-química do mel normalmente varia, sendo influenciada por diversos fatores como: condições climáticas, o nível de maturação, a espécie da abelha, o tipo de vegetação do qual o néctar se origina, entre outros. Outro aspecto que influencia diretamente na qualidade do mel são as etapas de extração, processamento e armazenamento realizadas pelo apicultor (Waltrich \& De Carvalho, 2020; Silva et al., 2011).

No Nordeste brasileiro a atividade apícola vem crescendo bastante, exercendo grande importância por ser uma alternativa rentável, além de adaptar-se bem ao clima do semiárido obtendo excelente produtividade, sendo utilizada como alternativa de renda para muitos produtores da agricultura familiar, contribuindo assim, com o desenvolvimento social e econômico da região. Apesar da diversidade de produtos apícolas, o mel é o principal produto explorado pelos consumidores e apicultores (Santos et al., 2020).

Os consumidores estão cada vez mais exigentes à procura de alimentos mais saudáveis, e o mel é um deles, porém seu consumo ainda está muito associado a questões medicinais. Portanto, conhecer o perfil de consumidores de mel é fundamental para ampliar o consumo desse produto como alimento e, consequentemente, potencializar o mercado apícola (De Novaes et al., 2021).

O mel para consumo humano deve ser processado em condições satisfatórias de Boas Práticas de Fabricação e não deve conter matérias estranhas ou contaminação microbiológica (De Assis Carvalho et al., 2020). As Boas Práticas de Produção de mel são diretrizes importantíssimas para a obtenção de um produto inócuo, saudável e puro para o consumo humano, e envolve todas as etapas do processo, desde o manejo no campo até o consumidor final. 
Muitos estudos são realizados sobre a qualidade físico-química dos méis produzidos no Brasil (De Souza et al., 2021; Nascimento et al., Alves et al., 2020; Ribeiro \& Starikoff, 2019; Souza, 2019; Silva et al., 2018; Borges et al., 2017), entretanto, pouco se sabe sobre as condições em que este é processado, envasado e comercializado. É necessário conhecer as condições da produção de mel para que a partir dos resultados obtidos, sejam feitas intervenções de modo que os apicultores e comerciantes consigam a melhoria da qualidade do mel e aumento da comercialização do produto.

Segundo Do Carmo Miranda e Domingues, (2020), as feiras livres estão presentes em todos os estados brasileiros, principalmente nas regiões Sudeste e Nordeste. Elas se destacam pelo importante papel para a comercialização de produtos provenientes do campo, como meio de desenvolvimento econômico local, com envolvimento de aspectos culturais e sociais relacionados ao contato entre a sociedade consumidora e produtores rurais familiares.

A comercialização do mel oriundo da agricultura familiar é realizada principalmente em feiras locais. Esse tipo de comércio faz parte do contexto social, cultural e histórico da sociedade, porém, a venda de produtos sem registros ou qualquer fiscalização prevalece nesse tipo de comércio. Portanto, a fiscalização por parte dos órgãos competentes se faz necessário para garantir alimento seguro ao consumidor (De Souza et al., 2021).

A exigência por produtos de qualidade disponíveis ao consumo humano reflete a necessidade de um maior controle durante o processo de produção (Ribeiro \& Starikoff, 2019).

Por ser um alimento de alto valor nutritivo e medicinal, o preço do mel, muitas vezes não é considerado acessível. Por consequência, o produto distribuído em feiras livres tende a sofrer adulterações, com o objetivo de torná-lo mais barato. Além disso, o produto é comercializado sem quaisquer requisitos básicos de higiene e, no que diz respeito à embalagem e rotulagem necessárias (Bastos, 2020; Gomes et al., 2017).

Alguns estudos tem analisado a qualidade do mel comercializado em feiras livres em diversas cidades do Brasil (De Assis Carvalho et al., 2020; Ribeiro, 2019; Dos Santos Picanço et al., 2018; Borges et al., 2017; Barbosa et al., 2016; Chaves, 2015; Abadio Finco, Moura \& Silva, 2010; Moreti et al., 2009). Entretanto ainda são escassos na literatura análise de qualidade de mel em Barreiras, bem como o perfil de consumo em relação ao produto, o perfil dos feirantes e apicultores que comercializam esse produto apícola.

Dessa forma, esse estudo teve como objetivo avaliar as condições de comercialização dos méis nas feiras livres da cidade de Barreiras - Bahia, realizar um levantamento do perfil dos consumidores, comerciantes e dos apicultores e meliponicultores da cidade de Barreiras-Ba.

\section{Metodologia}

\subsection{Perfil do Consumidor de Mel}

Foi aplicado questionário padronizado e estruturado, para traçar o perfil do consumidor de mel da cidade de Barreiras - BA. A elaboração do questionário buscou conhecer o perfil social dos consumidores, além de identificar quais os critérios de escolha do mel, como: formas de utilização do produto, a opinião quanto ao preço, local de aquisição, embalagem e outras informações. Optou-se por entrevistas diretas com questões fechadas.

Foi elaborado um questionário com 28 perguntas, o qual foi aplicado a 110 pessoas que residem na cidade de Barreiras - BA. A pesquisa foi realizada, através de questionário eletrônico, encaminhando por WhatsApp, entre os meses de Julho e Agosto de 2021.

Os dados foram agrupados por semelhança das respostas, posteriormente foram calculados em relação à frequência relativa de cada variável resposta através do programa Microsoft Excel (versão 2018). 


\subsection{Perfil dos feirantes que comercializam méis nas feiras livres}

Para avaliar o perfil dos vendedores de méis nas feiras livres da cidade de Barreiras-Ba, foi feito uma pesquisa exploratória, fundamentada em análise qualitativa e interpretativa, baseada na realidade observada.

A avaliação foi realizada durante o mês de Julho 2021, no município de Barreiras - BA. Foram realizadas visitas em duas feiras livres (denominadas: F1e F2). Os dados foram estruturados por meio de um questionário previamente estabelecido, contendo informações acerca do perfil social dos feirantes e conhecimentos gerais dos méis comercializados por eles. Foram visitadas no total de 6 barracas, sendo 3 na Feira F1 e 3 na Feira F2.

Os preenchimentos foram feitos por meio de observações no próprio local. Optou-se por entrevistas diretas com questões fechadas e apenas uma questão subjetiva, sendo que a entrevistadora fazia as perguntas e anotava as respostas. Tal avaliação foi realizada durante a coleta das amostras de méis, na qual também foram observadas: tipos das embalagens, bem como a presença de informações dos rótulos, e local de armazenamento dos produtos.

\subsection{Avaliação do Processamento do Mel e o Perfil dos Apicultores e Meliponicultores da Região Oeste da Bahia}

Para a verificação das condições locais de Processamento do mel, foram entrevistados 10 produtores de uma Associação de Apicultores e Meliponicultores da região Oeste da Bahia, a fim de identificar as práticas utilizadas no processo de extração e envase do produto, além de obter informações a respeito do perfil dos apicultores. Em função da pandemia do Coronavírus, a entrevista foi realizada através de preenchimento de questionário eletrônico, encaminhando por WhatsApp, entre os meses de Julho e Agosto de 2021.

Foi elaborado um questionário com 25 questões, contendo perguntas relacionadas a produção, a higienização do local e dos equipamentos, bem como perguntas relacionadas ao tipo de embalagem utilizada para comercialização, rotulagem e os fatores limitantes para o desenvolvimento da atividade apícola/meliponícula na região Oeste da Bahia.

\section{Resultados e Discussão}

\subsection{Perfil do Consumidor de Mel}

De acordo com a análise dos dados, cerca de $67 \%$ dos entrevistados pertenciam ao sexo feminino, $33 \%$ das pessoas estavam dentro da faixa etária entre 36 a 45 anos e a maior parte das pessoas (51\%) recebem entre 2 a 5 salários mínimos. Em relação ao nível de escolaridade, $41 \%$ dos entrevistados afirmaram possuir pós-graduação.

Van Den Bree, Przybeck e Cloninger (2006), ressaltam que para caracterizar o perfil de um consumidor é de extrema importância não esquecer os fatores demográficos, como idade, gênero, classe econômica a qual pertence, como também o grau de escolaridade, isso porque, estes parâmetros estão diretamente associados aos comportamentos de consumo individuais por inferirem valores de status sociais.

Dados de outros autores demonstram maior predominância do gênero feminino, no que se trata do consumo de mel, como Santos et al., (2020) 52,30\% e Silva et al., (2020) 53,60\%.

Conforme defendido por alguns autores, a variável demográfica que tem maior influência no consumo do mel é o gênero. Segundo eles, embora o mundo tenha passado por mudanças demográficas, o gênero feminino continua sendo a responsável pela obtenção dos alimentos para o lar. Sendo dona de casa ou não, é a mulher que identifica a necessidade, busca informações, avalia, escolhe a marca e decide onde comprar o produto (Mota et al., 2018).

Conforme mostrado na Tabela 1, a grande maioria dos entrevistados afirmaram consumir mel, e a regularidade desse consumo acontece pelo menos uma vez por mês, de acordo com 47,12\% das pessoas. Os entrevistados que consomem mel com maior frequência, (diariamente, uma vez por semana ou mais) atingiram o índice de 37,2\%, e os que fazem uso com menor frequência, (uma vez por ano) correspondem a 12,7\%. 
O consumo do mel como remédio é de 33,6\% no presente estudo. Conforme Peralta e Nondilho (2019), a utilização do mel como remédio caseiro é bastante difundida entre a população brasileira, principalmente para o tratamento das doenças mais comuns, como gripe, dor de garganta e febre.

De acordo com a Tabela 1, a maioria das pessoas $(61,8 \%)$ fazem o uso do mel como alimento. Do ponto de vista nutricional, o mel além de ser um adoçante natural pois se configura em um alimento rico em carboidratos, apresentando vários nutrientes minerais. Além de atuar no fortalecimento do sistema imunológico, estimula a produção de anticorpos e a atividade das células de defesa, bem como o combate a radicais livres maléficos ao organismo humano (Dos Santos Vasconcelos et al., 2021; Teixeira, 2017).

Quanto aos hábitos de compra, 43,6\% dos participantes, afirmaram preferir adquirir o produto diretamente com o produtor (Tabela 1). Esses dados corroboram com os dados obtidos por Novaes et al., (2021), no qual 33,4\% dos entrevistados optam por adquirir o mel diretamente com o produtor.

Tabela 1: Perfil de consumo de mel na cidade de Barreiras, Bahia.

\begin{tabular}{|c|c|c|c|}
\hline \multicolumn{2}{|c|}{ Consumo de mel (\%) } & \multicolumn{2}{|c|}{ Frequência (\%) } \\
\hline Sim & 94,5 & Diariamente & 8,2 \\
\hline Não & 4,5 & Uma vez na semana & 10,9 \\
\hline \multicolumn{2}{|c|}{ Motivo (\%) } & Mais de uma vez na semana & 18,1 \\
\hline É gostoso/saboroso & 32,7 & Uma vez por mês & 47,12 \\
\hline É saudável & 35,5 & Uma vez por ano & 12,7 \\
\hline Serve como remédio & 26,4 & Não consumo mel & 18 \\
\hline Prescrição médica & 0,9 & \multicolumn{2}{|c|}{ Local de compra (\%) } \\
\hline Outros fins & 4,5 & Supermercado & 25,5 \\
\hline \multicolumn{2}{|c|}{ Forma de utilização (\%) } & Diretamente do produtor & 43,6 \\
\hline Uso na alimentação & 61,8 & Feira Livre & 20 \\
\hline Uso como remédio & 33,6 & Vendedor Ambulante & 8,2 \\
\hline Uso como cosmético & 1,8 & Farmácia & 0,9 \\
\hline Não sei informar & 2,7 & Outros & 1,8 \\
\hline
\end{tabular}

Fonte: Autores (2021).

Conforme análise de Zamberlan e Santos (2010), os consumidores que compram o mel diretamente do produtor, acreditam que desta forma é possível reduzir os riscos de levar para casa um produto adulterado. Já Dos Santos Picanço et al., (2018) apontam as feiras livres 36,47\%, como o local mais escolhido para a compra do produto.

Em relação ao questionamento sobre o valor pago no mel, a maioria das pessoas $(52,7 \%)$ informaram que o valor cobrado é alto. No entanto o valor do produto apícola não é o critério mais utilizado no momento da compra, conforme ilustrado na Figura 1. 
Figura 1: Critérios no momento de compra dos consumidores de mel da cidade de Barreiras, Bahia.

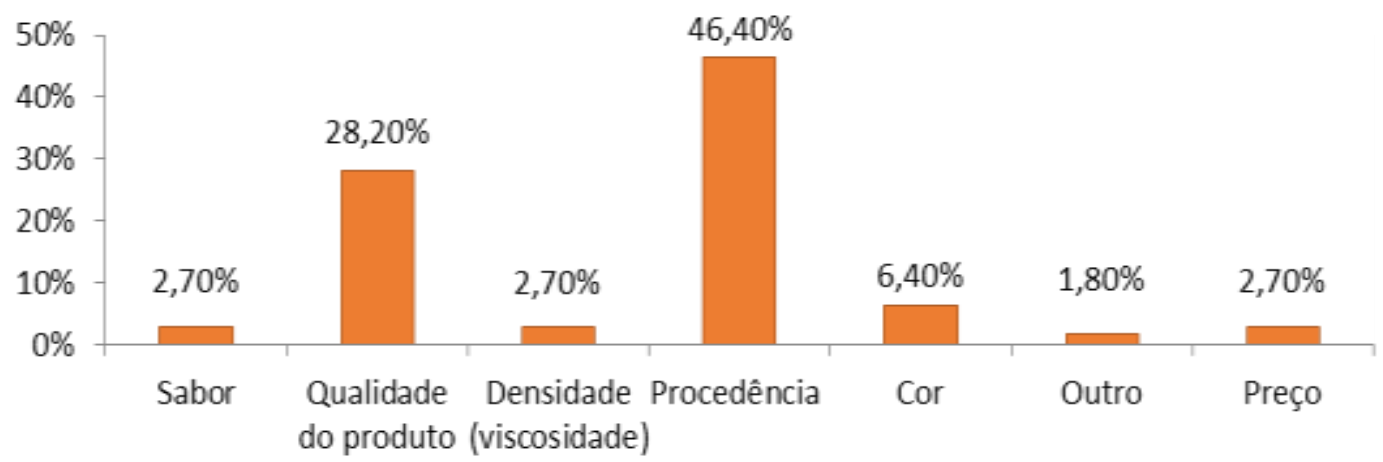

Fonte: Autores (2021).

A procedência do mel, ou seja, o local de onde esse mel é colhido e ou processado, foi o critério justificado por 46,40\% no momento da aquisição do produto, seguido da qualidade do mel (Figura 1). De acordo com Alves et al., (2017), a qualidade do mel está associada a um conjunto de fatores, como as condições climáticas, florada, estágio de maturação, espécie de abelha, processamento e armazenamento. A soma desses fatores influência diretamente a cor, sabor e densidade do mel.

Quanto às embalagens do mel, 70\% dos entrevistados relataram que a embalagem influencia no consumo e compra do produto apícola. Em feiras livres na cidade de Barreiras-BA, os méis são comercializados em embalagens plásticas com diferentes volumes (garrafa PET) reaproveitadas de outros alimentos. Todas as embalagens dos méis analisados, nenhuma apresentou identificação de rotulagem com informações sobre origem, registro, peso, validade e outras informações que são obrigatórias em alimentos embalados na ausência do consumidor (De Souza, 2019).

Em relação à rotulagem, $60 \%$ das pessoas relataram que o mel adquirido por eles não possuíam rotulagem, apesar da maioria dos entrevistados $(73,6 \%)$ considerarem o produto mais confiável com a presença de rótulo.

Machado et al. (2006), enfatiza que os rótulos presentes nas embalagens de alimentos são elementos indicadores, que serve como informação ao consumidor no momento da compra, indicando inclusive a forma correta de conservação e preparo dos produtos alimentícios (quando for o caso), e como consequência, aumentar a eficiência do mercado e bem-estar do consumidor.

Por ser classificado como um produto de origem animal, o mel necessita de Serviço de Inspeção, seja ela Municipal (SIM), Estadual (SIE) ou Federal (SIF) para ser comercializado, garantindo dessa forma a segurança e qualidade do produto para o consumidor (Machado, 2017). Ao serem questionados a respeito da inspeção de produtos de origem animal, 48,2\% dos entrevistados afirmaram não ter conhecimento sobre o assunto e metade das pessoas disseram não conhecer ou saber do que se refere as siglas (SIM), (SIE), e (SIF).

De acordo com Lima, (2019), o conhecimento sobre a qualidade do mel é muito importante, pois se trata de alimento e tudo que o ser humano coloca para dentro do seu organismo, necessita de cuidados especiais por ser questão de saúde.

A maioria dos entrevistados $(88,2 \%)$ afirmaram que a falta de propaganda atrelada a falta de conhecimento dos benefícios do mel, influenciam na frequência do consumo do produto apícola.

Alguns autores apontam o mesmo problema como barreiras para o consumo mais frequente do mel. Segundo os resultados de pesquisas em relação ao consumo do produto, um dos problemas percebidos é a falta de conhecimento acerca das propriedades do mel, dos seus benefícios e usos, além da falta de esforço de promoção do produto, sobretudo para estimular a demanda primária, pois a maioria dos entrevistados que conhecem os benefícios do mel o consomem com maior frequência (Silva et al., 2018; Zamberlan \& Santos, 2010; Zamberlan et al., 2006). 


\subsection{Perfil dos feirantes que comercializam méis nas feiras livres}

Conforme abordagem aos feirantes que comercializam mel nas feiras livres da cidade de Barreiras-Ba, a grande maioria exerce a atividade de feirante há mais de 11 anos, e possuem idade acima dos 40 anos. Grande parte (60\%) relatou nunca ter participado de eventos relacionados a boas práticas de manipulação de alimentos, como cursos e palestras.

Segundo Almeida e Pena (2011), diversos estudos centrados na esfera dos riscos biológicos demonstram as inadequadas condições de higiene em feiras livres, aliadas às adversidades da estrutura física e ao precário conhecimento dos feirantes sobre as boas práticas de manipulação e comercialização de alimentos.

Ao término do expediente, os feirantes não possuem um local adequado para armazenamento dos produtos. Dessa forma, foi possível observar condições inadequadas de armazenamento do mel, pois além da utilização de embalagens não recomendadas, como embalagens reutilizáveis e danificadas, havia também incidência de luz solar direta nos recipientes que estavam dispostos em bancadas (Figura 2).

Figura 2: Condições de armazenamento de méis comercializados nas feiras livres da cidade de Barreiras - BA.

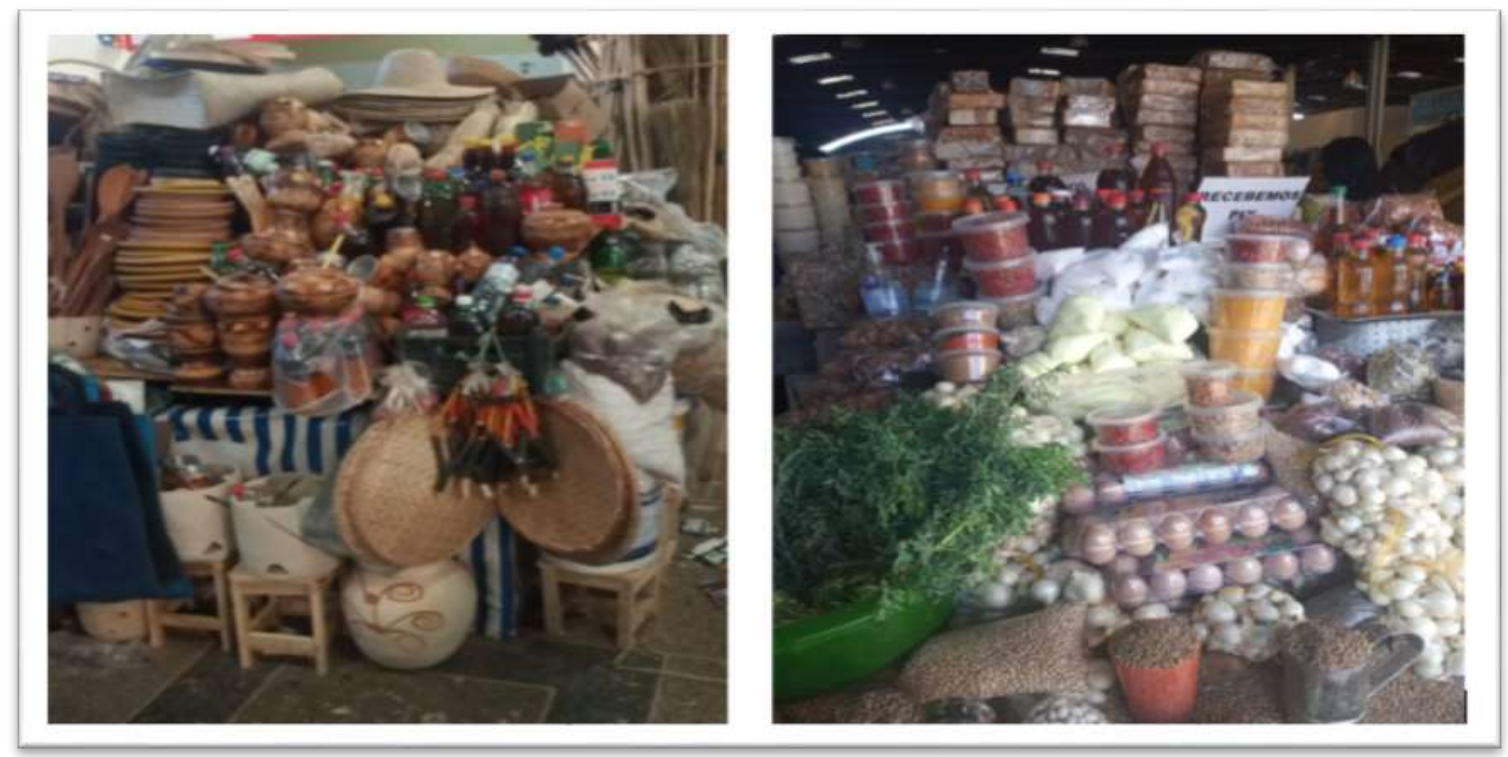

Fonte: Autores (2021).

De acordo com o Regulamento Técnico para Fixação de Identidade e Qualidade do Mel, o mel pode apresentar-se a granel ou fracionado, devendo ser acondicionado em embalagem apta para alimento, adequada às condições previstas de armazenamento e que confira proteção adequada contra contaminação. Além disso, não deve conter substâncias estranhas, de qualquer natureza, tais como insetos, larvas, grãos de areia e outros (Brasil, 2000).

Ao escolher a embalagem certa para comercialização de mel deve-se estar atento para as que são próprias para a conservação de produtos alimentícios. Além disso, um dos fatores que também prejudica o produto é a luminosidade, que ao entrar em contato com o mel o escurece, por isso deve ser armazenado em ambientes sem a presença de luz, frescos e com a temperatura média de 25 a $30^{\circ} \mathrm{C}$ (Roberts \& Myrrha, 2014).

Outro ponto importante observado nas barracas que dispõem de mel para a venda, foi o fato dos feirantes comercializarem diversos produtos ao mesmo tempo, entre eles produtos comestíveis e não comestíveis (Figura 2), de maneira desorganizada, de tal forma que os próprios feirantes não conseguiam identificar se o produto exposto era de fato mel de abelha. 
O mercado apícola está interessado diretamente na qualidade do produto que está sendo comprado e a embalagem influencia diretamente na comercialização, por isso o formato, tamanho e rotulagem das embalagens para produtos apícolas devem ser atraentes, adequadas ao gosto para serem aceitas pelo consumidor (Silva et al., 2009).

Diante o questionamento do motivo pelo qual eles trabalham com tantos produtos, além do mel, os feirantes responderam de forma unânime que só a venda do mel não gera para eles um lucro considerável e, ao fornecerem mais opções de produtos, eles conseguem fidelizar o cliente.

Um fato preocupante em relação aos vendedores de mel nas feiras livres da cidade de Barreiras-Ba é a falta de conhecimento sobre o produto comercializado por eles, como a forma que o mel foi colhido, as condições básicas de higiene durante o processo, o tempo de colheita e forma de acondicionamento do produto. A única informação relatada sobre o mel vendido por eles foi a região de onde o produto é colhido.

\subsection{Avaliação do Processamento do Mel e o Perfil dos Apicultores e Meliponicultores da Região Oeste da Bahia}

Conforme os dados obtidos, metade dos apicultores e meliponicultores entrevistados apontaram a cidade de BarreirasBA como a região na qual eles desenvolvem a atividade apícola/meliponícula. Essa produção de mel é vendida diretamente ao consumidor, conforme relatado pela grande maioria dos produtores $(83,3 \%)$.

Apesar de grande parte dos apicultores e meliponicultores $(66,7 \%)$ informarem que já participaram de cursos voltados as Boas Práticas de Fabricação e Processamento de Alimentos, a maioria não coloca em prática esses conhecimentos na hora de realizar a higiene pessoal, do ambiente de trabalho e nem dos equipamentos utilizados na produção e envase do mel.

Conforme explica Villas-Bôas (2012), todos os equipamentos e materiais diretamente envolvidos na manipulação do mel (equipamentos de coleta e beneficiamento, recipientes de armazenamento, envases, etc.) devem ser higienizados em água limpa e abundante com sabões sem cheiro, como sabão de coco ou detergente neutro, e sempre que possível, fervê-los ou enxaguá-los com água fervente.

A legislação brasileira para Mel e produtos apícolas (Brasil, 2000) é de conhecimento da maioria dos produtores $(88,3 \%)$, no entanto a grande maioria dos apicultores e meliponicultores não segue a legislação em relação a coleta e processamento. Apenas 16,7\% dos produtores possuem um local apropriado para coleta, extração, processamento e envase do mel. Ananias, (2010) ressalta que a colheita e a extração começam desde a instalação do apiário, caso o procedimento não seja feito em local apropriado, a qualidade do mel dentro das colônias pode ser comprometido.

Após sua colheita, o mel continua sofrendo modificações físico-químicas e sensoriais, gerando a necessidade de processá-lo de acordo com as boas práticas de produção, a fim de garantir um produto de boa qualidade (Araújo, Silva \& Souza, 2006; Silva, 2007).

De acordo com os dados da Tabela 2, o uso da bisnagas de plástico é o tipo de embalagem utilizada pela maioria dos produtores para o envaso do mel, seguidos por $14,3 \%$ que utilizam a garrafa de vidro e $28,6 \%$ optam pelo o uso da garrafa de plástico (PET).

Teixeira, (2015) explica que os potes de plástico têm menor custo que os de vidro, são mais leves e são bastante resistentes. Em contrapartida, no varejo a embalagem mais usada é o pote de vidro, considerada mais higiênica pelos consumidores, e que também consegue mostrar com mais fidelidade a coloração, a textura e o brilho do mel, ajudando, inclusive, a destacá-los. Já os potes ou as bisnagas, que possuem bico dosador e facilitam a retirada do produto, são consideradas pela maioria dos consumidores como a mais prática. 
Tabela 2: Aspectos relacionados à embalagem, rotulagem do mel comercializado pelos apicultores e meliponicultores da Região Oeste da Bahia.

\begin{tabular}{|c|c|c|c|}
\hline \multicolumn{2}{|c|}{ Tipo de embalagem (\%) } & \multicolumn{2}{|c|}{ Usa embalagens reutilizáveis (\%) } \\
\hline Garrafa de plástico (PET) & 28,6 & Sim & 38 \\
\hline Garrafa de vidro & 14,3 & Não & 63 \\
\hline Pote de Vidro & 0 & \multirow{2}{*}{\multicolumn{2}{|c|}{$\begin{array}{c}\text { Distribuição do mel envasado, pronto para o } \\
\text { consumo }(\%)\end{array}$}} \\
\hline Bisnagas de Plástico & 57,1 & & \\
\hline Outros & 0 & Sim & 86 \\
\hline \multicolumn{2}{|c|}{ Selo de Inspeção (\%) } & Não & 14 \\
\hline $\begin{array}{l}\text { SIM } \\
\text { SIE }\end{array}$ & $\begin{array}{l}0 \\
0\end{array}$ & \multicolumn{2}{|c|}{ As embalagens do méis possuem rótulos (\%) } \\
\hline SIF & 14,3 & Sim & 33,3 \\
\hline Não possui & 85,7 & Não & 67,7 \\
\hline
\end{tabular}

Fonte: Autores (2021).

Em tais embalagens $66,7 \%$ dos apicultores e meliponicultores afirmaram comercializar o produto sem a presença de rotulagem, e apenas $14,3 \%$ dos produtores possuem o registro do produto no Ministério da Agricultura, Pecuária e Abastecimento (MAPA), obtendo o Selo de Inspeção Federal (SIF), conforme Tabela 02.

Para os apicultores e meliponicultores do presente estudo, a falta de incentivo de órgãos públicos é um fator limitante para o desenvolvimento da atividade apícola/meliponicultura, como reflete o (Figura 3).

Figura 3: Fatores limitantes para o desenvolvimento da atividade apícola/meliponicultura na Região Oeste da Bahia.

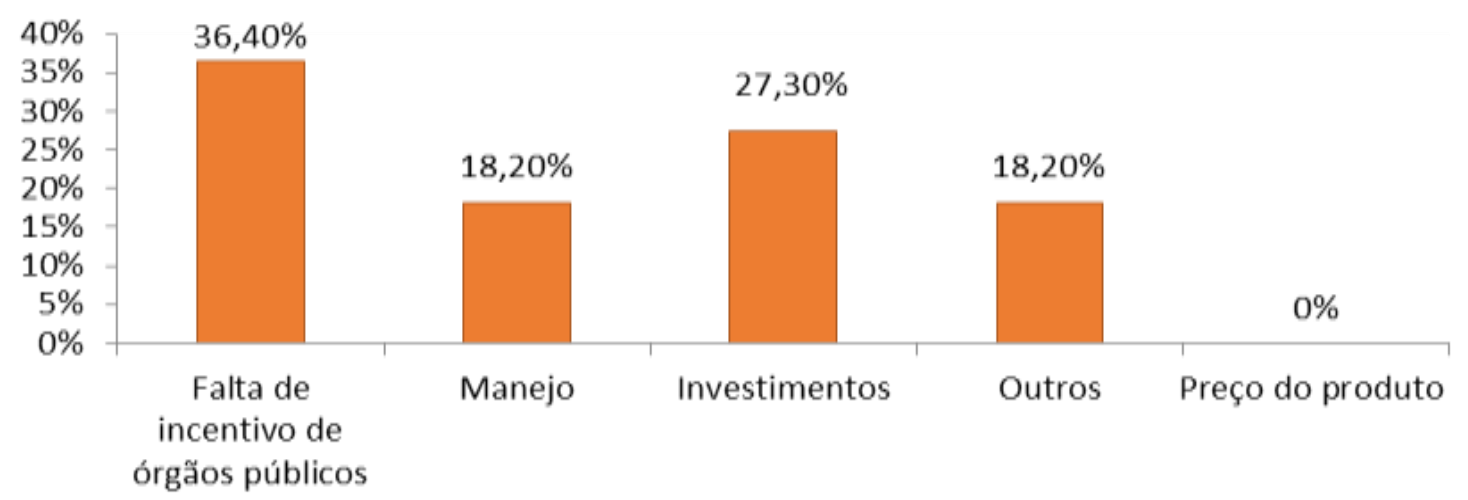

Fonte: Autores (2021).

Outros autores também apontam o mesmo entrave no setor, além da desqualificação técnica dos recursos humanos inseridos na atividade, desorganização e falta de coordenação da cadeia produtiva apícola e, consequentemente, o comportamento inadequado, de modo geral, por parte de produtores (Assad et al., 2018; Oliveira, 2015; Sordi \& Schlindwein, 2014; Bonila, 2012).

\section{Considerações Finais}

A pesquisa foi uma importante ferramenta para identificação do perfil dos consumidores de mel, é necessário assimilar os desejos e necessidades de quem compra o produto. Foi possível notar a falta de informações por parte dos consumidores em relação ao consumo do produto sem rótulo e em relação aos benefícios ocasionados pelo consumo do mel. É 
imprescindível uma divulgação sobre a importância do consumo desse alimento e de comprar somente se tiver algum selo de inspeção, seja municipal, estadual ou federal.

Em relação aos feirantes que comercializam o mel, pode constatar que os locais de comercialização dos produtos, que são as feiras, não possuem condições adequadas de venda, exposição e armazenamento. É necessário que os órgãos de fiscalização sanitária façam um trabalho de treinamento sobre boas práticas de fabricação e que passem a fiscalizar com mais frequência.

Sobre os apicultores e meliponicultores, conclui-se que boa parte destes possuem conhecimentos básicos em relação à manipulação correta dos alimentos. Embora tenham conhecimento a respeito da legislação para Mel e Produtos apícolas, algumas práticas não aceitáveis pela legislação ainda é muito comum, como a comercialização do produto sem rótulo e sem inspeção, bem como o uso de embalagens reutilizáveis.

\section{Agradecimentos}

Os autores agradecem ao Instituto Federal de Educação, Ciência e Tecnologia da Bahia, Campus Barreiras, por seu apoio financeiro.

\section{Referências}

Abadio Finco, F. D. B., Moura, L. L., \& Silva, I. G. (2010). Propriedades físicas e químicas do mel de Apis mellifera L. Food Science and Technology, 30(3), 706-712.

Alves, L. R. P. Análise de Qualidade e Levantamento dos Perfis dos Produtores, Comerciantes e Consumidores de Mel da Cidade de Barreiras - Ba. Barreiras: IFBA.

Alves, W. S., Lisbôa, C. G., Silva, J. N., \& Oliveira, A.P. Estudo comparativo da qualidade físico química de mel orgânico para exportação. Congresso Internacional de Ciências Agrárias- PDVAgro. Pernambuco, 2017.

Almeida, M. D., \& Pena, P. G. L. (2011). Feira livre e risco de contaminação alimentar: estudo de abordagem etnográfica em Santo Amaro, Bahia. Revista Baiana de Saúde Pública, 35(1), 110-110.

Ananias, K. R. (2010). Avaliação das condições de produção e qualidade de mel de abelhas (Apis Mellifera L.) produzido na microrregião de Pires do Rio, no Estado de Goiás. Goiás.

Anjos, J. S. D. (2018). Perfil dos consumidores de mel no município de Chapadinha-MA. Chapadinha.

Assad, A., Da Rocha Neto, A. C., Marinho, B., Rehder, C., Matos, C., Menezes, C., \& de Carvalho, W. A. F. (2018). Plano de fortalecimento da cadeia produtiva da apicultura e da meliponicultura do Estado de São Paulo. Embrapa Pecuária Sudeste -Livro científico (ALICE).

Barbosa, S., Ribeiro, J. L. \& Ubaldo, J. C. S. R. Características físico-químicas de méis comercializados na cidade de Sete Lagoas-MG. In: XXV Congresso Brasileiro de Ciência E Tecnologia de Alimentos, n 25, 2016.

Bastos, G.D. (2020). Avaliação da qualidade físico-química de méis obtidos de produtores rurais da região do Alto Uruguai-RS.

Bonilla, E. B. P. (2012). Caracterização de cadeia produtiva do mel catarinense: os casos das associações de apicultores de Bom Retiro e da Encosta da Serra.

Borges, J. G., Pinheiro, J. V. R., de Andrade, R. B., \& Telles, C. P. (2017). Qualidade de mel comercializado em feiras livres de Salvador e Petrolina. Revista Brasileira de Produtos Agroindustriais, Campina Grande, 19(3), 231-240.

Brasil. (2000) Ministério de Agricultura e do Abastecimento. Instrução Normativa No 11, de 20 de outubro de 2000. DOU, n 204 , seção 1, p. $15-17,23$.

Chaves, W. (2015). Qualidade de Mel Comercializado em Feiras Livres do Município de Teresina, Piauí. In XXV Congresso Brasileiro de Zootecnia. Resumos... Fortaleza: ZOOTEC.

De Assis Carvalho, R., Ribeiro, A. C., Lima, C. M., da Silva Mariz, W. P., Silva, L. S., da Silva, A. M., \& Trombete, F. M. (2020). Assessment of adulteration and mycoflora identification of honey samples marketed in the metropolitan region of Belo Horizonte, Brazil. Research, Society and Development, 9(7), e440974246-e440974246.

De Novais, J. S., Marques, G. V., de Oliveira, R. J. B., \& da Silva Balio, A. R. (2021). Perfil dos consumidores de mel em feiras livres de Porto Seguro, Bahia, Brasil. International Journal of Business Marketing, 6(1), 45-57.

De Souza, C. F., Alves, L. R. P., Tulini, F. L., Mamede, A. M. G. N., De Araújo Santana, A. C. B., \& Lima, Í. A. Parâmetros de qualidade de méis inspecionados comercializados na cidade de Barreiras-Bahia. Research, Society and Development, 10(1), e28710110959-e28710110959, 2021. 
Dos Santos Picanço, Y., Oliveira, S. S., Almeida, M., Otani, F. S., Pereira, E. J., \& dos Santos, G. C. (2018). Análise de atividade de água e umidade na qualidade do mel produzido em comunidades da reserva extrativista Tapajós-Arapiuns, Santarém, Pará. Revista Agroecossistemas, 10(2), 1-10.

Dos Santos Vasconcelos, E., dos Santos Silva, S., Pamplona, V. M. S., Rodrigues, A. E., de Oliveira, G. T., da Silva, M. V. O., \& Dias, L. D. N. S. (2021). Análise sensorial e aceitabilidade de méis de diferentes floradas oriundas de três municípios do Nordeste Paraense. Research, Society and Development, 10(6), e16010615521-e16010615521.

Do Carmo Miranda, G. M., \& Domingues, H. (2020). Diagnóstico da feira livre: um estudo de caso em São Domingos do Prata, Brasil. Research, Society and Development, 9(7), e358973002-e358973002.

De Souza, C F. (2019). Avaliação físico-química de méis artesanais e industrializados comercializados na cidade de Barreiras - BA. Barreiras - Bahia, Instituto Federal da Bahia.

Gomes, V. V., Dourado, G. S., Costa, S. C., Lima, A. K. O., Silva, D. S., Bandeira, A. M. P., \& Taube, P. S. (2017). Avaliação da qualidade do mel comercializado no oeste do Pará, Brasil. Revista Virtual de Química, 9(2), 815-826.

Lima, L. L. B. (2019). Perfil socioeconômico e conhecimento dos parâmetros de qualidade por parte de produtores e consumidores de mel no Distrito Federal.

Machado, S. S., Santos, F. O. D., Albinati, F. L., \& Santos, L. P. R. (2008). Comportamento dos consumidores com relação à leitura de rótulo de produtos alimentícios. Alimentos e Nutrição Araraquara, 17(1), 97-103.

Machado, L. V. (2017). Implementação do sistema brasileiro de inspeção de produtos de origem animal (SISBI-POA) em Santa Maria-RS.

Mota, A. V., Garcia, A. A., da Silva, A. O., de Souza, A. M. B., Silva, D. A. S., Júnior, F. O. P., \& Lima, R. F. (2018). Estudo do perfil socioeconômico dos consumidores de mel da região nordeste paraense: uma abordagem a partir do município de terra alta. 1-388.

Moreti, A. C. D. C. C., Sodré, G. D. S., Marchini, L. C., \& Otsuk, I. P. (2009). Características físico-químicas de amostras de méis de Apis mellifera L. do estado do Ceará, Brasil. Ciência e Agrotecnologia, 33, 191-199.

Nascimento, A. M. da S., Souza, I. B. de, Santos, R. R. dos, Ciências, tecnologia e inovação [livro eletrônico]: do campo à mesa. In: Alves, L. R. P., Souza, C. F. de, Santana, A. C. B. de A., TulinI, F. L. \& Lima, Í. A. Qualidade de méis comercializados em feiras livres no município de Barreiras-Ba. PE. Instituto Internacional Despertando Vocações, 2020. 789 - 806

Peralta, I. M. R., \& Nondillo, A. (2020, February). Uso do mel na medicina popular na cidade de Bento Gonçalves-RS. In MTC-Mostra Técnico-Científica 2019 IFRS - Campus Bento Gonçalves.

Ribeiro, R., \& Starikoff, K. R. (2019). Avaliação da qualidade físico-química e microbiológica de mel comercializado. Revista de Ciências Agroveterinárias, 18(1), 111-118

Ribeiro, R. D. O. R., da Silva, C., Monteiro, M. L., Baptista, R. F., Guimarães, C. F., Mársico, E. T., ... \& da Silva Pardi, H. (2009). Avaliação comparativa da qualidade físico-química de méis inspecionados e clandestinos, comercializados no estado do Rio de Janeiro, Brasil. Revista Brasileira de Ciência Veterinária, 16(1).

Rivera, M. (2005). Análisis de los factores demográficos en el consumo de miel de abeja en las familias de la ciudad de Aguascalientes. In CONGRESSO ESTATAL LA INVESTIGACIÓN EN EL POSGRADO (Vol. 1).

Roberts, J., \& Myrrha, N. (2016). SEBRAE: Serviço Brasileiro de Apoio às Micro e Pequenas Empresas. In Institutional Case Studies on Necessity Entrepreneurship. Edward Elgar Publishing.

Santos, C. R., de Souza Santos, J., Santos, D. R., dos Santos, M. R., \& do Nascimento, G. R. (2020). Perfil dos consumidores do mel de Apis mellifera em Ubaíra-BA. Agropecuária científica no semiárido, 16(1), 15-19.

Silva, M. B. L., Chaves, J. B. P., Valente, M. E. R., Gomes, J. C., \& Oliveira, G. F. (2011). Qualidade de méis produzidos por apicultores e méis provenientes de entrepostos registrados no Serviço de Inspeção Federal. Arquivo Brasileiro de Medicina Veterinária e Zootecnia, 63(4), 1043-1045.

Silva, M. G. C. D., Figueira, P. T., Hoscheid, J., \& Fukumoto, N. M. (2018). Análise das propriedades físico-químicas de amostras de mel comercializado em feiras livres do município de Assis Chateaubriand, PR. Higiene Alimentar, 32(278/279).

Silva, K. D. F. N. L., Queiroz, A. J. D. M., De Figueiredo, R. M. F., Silva, C. T. S., \& Dos Santos, K. D. S. M. (2009). Características físico-químicas de mel produzido em Limoeiro do Norte durante o armazenamento. Revista Caatinga, 22(4), 246-254.

Sordi, V. F., \& Schlindwein, M. M. (2014). Os Principais Benefícios da Atividade Apícola e os Entraves para seu Desenvolvimento no Estado de Mato Grosso do Sul. Revista em Agronegócio e Meio Ambiente, 7(3).

Van Den Bree, M. B., Przybeck, T. R., \& Cloninger, C. R. (2006). Diet and personality: Associations in a population-based sample. Appetite, 46(2), 177-188.

Villas-Bôas, J. (2012). Manual tecnológico: mel de abelhas sem ferrão.

Waltrich, C., \& de Carvalho, L. F. (2020). Estudo de propriedades físicas e químicas durante armazenamento de mel produzido na região de Blumenau, Brasil. Research, Society and Development, 9(7), e495974070-e495974070.

Zamberlan, L., \& Santos, D. D. (2010). O comportamento do consumidor de mel: um estudo exploratório. Revista de Administração e Ciências Contábeis, 5(10), 45-50.

Zamberlan, L., Sparemberger, A., Wagner, A., \& Sartor, S. (2006). O comportamento do consumidor de produtos agroalimentares: uma avaliação de atitudes no consumo de mel. Encontro nacional de engenharia de produção, 26, 1-9. 